\title{
Comparative effectiveness of aggressive intravenous fluid resuscitation with lactated Ringer's solution and rectal indomethacin therapy in the prevention of pancreatitis after endoscopic retrograde cholangiopancreatography: a double blind randomised controlled clinical trial
}

\author{
Abdolrahim Masjedizadeh ${ }^{1}$, Payman Fathizadeh², Nima Aghamohamadi ${ }^{1}$ \\ ${ }^{1}$ Research Center for Infectious Diseases of Digestive System, Ahvaz Jundishapur University of Medical Sciences, Ahvaz, Iran \\ ${ }^{2}$ David Geffen School of Medicine at UCLA, University, Los Angeles, California, USA
}

Gastroenterology Rev 2017; 12 (4): 271-276

DOI: https://doi.org/10.5114/pg.2017.72102

Key words: endoscopy, cholangiopancreatography, inflammation, pancreatitis, indomethacin.

Address for correspondence: Dr. Nima Aghamohamadi, Research Center for Infectious Diseases of Digestive System, Ahvaz Jundishapur University of Medical Sciences, Azadegan Boulevard, Imam Khomeini Hospital, 6193673166 Ahvaz, Iran, phone: +98 9166111886 , e-mail: draghamohamadi1@gmail.com

\begin{abstract}
Introduction: There is growing evidence indicating the aggressive intravenous fluid resuscitation (IVFR) can decrease the rate of pancreatitis; however, to the best of our knowledge it has not been well studied in a post-endoscopic retrograde cholangiopancreatography (post-ERCP) setting.

Aim: To compare the effects of aggressive IVFR and rectal indomethacin (RI) in preventing pancreatitis after ERCP.

Material and methods: This is a double blind randomised controlled clinical trial on 186 patients undergoing ERCP in Ahvaz, Iran. The inclusion criteria were ERCP for standard clinical indications such as choledocholithiasis, bile duct leak, and biliary obstruction. The IVFR group $(n=62)$ received a bolus of $20 \mathrm{ml} / \mathrm{kg}$ of body weight lactated Ringer's solution (LRS) immediately after ERCP, followed by $3 \mathrm{ml} / \mathrm{kg} / \mathrm{h}$ maintenance for $8 \mathrm{~h}$. The RI group $(n=62)$ received $50 \mathrm{mg}$ rectal indomethacin immediately before procedure and $12 \mathrm{~h}$ after ERCP. The control group $(n=62)$ did not receive any treatment.

Results: Post-ERCP pancreatitis in IVFR, rectal indomethacin, and control groups occurred in 8 (12.9\%), 16 (25.8\%), and 20 (32.3\%) patients $(p=0.036)$. Pancreatic pain was reported in $13(21 \%), 21(33.9 \%)$, and $27(43.5 \%)$ patients in the IVFR, RI, and control group $(p=0.046)$. The serum amylase level increased over $24 \mathrm{~h}$ after intervention in all three groups. The mean serum amylase level $8 \mathrm{~h}$ after intervention in the IVFR patients was lower than the RI and control groups.

Conclusions: Intravenous fluid resuscitation with LRS was more effective in preventing post-ERCP pancreatitis in comparison to the rectal indomethacin and control group.
\end{abstract}

\section{Introduction}

Pancreatitis is one of the most important complications of endoscopic retrograde cholangiopancreatography $(E R C P)$, with considerable morbidity and possible mortality [1-3]. Corticosteroids, protease inhibitors, and octerotide have not been shown to reduce the rate of this complication [4-6]. Administration of rectal indomethacin, however, may decrease this complication in high-risk patients [7]. Intravenous fluid resuscitation (IVFR) improves clinical outcome in acute pancreatitis and organ damage by increasing tissue perfusion and oxygenation, and preventing cell injury cascades [1, 4, 8]. Hydration with lactated Ringer's solution (LRS) can avert acidosis, avoid zymogen activation, and prevent inflammation cascade in the pancreas [5]. There is growing evidence indicating that aggressive IVFR can decrease the rate of pancreatitis; however, to the best of our knowledge it has not been well studied in post-ERCP setting.

\section{Aim}

The aim of this study was to compare the effect of aggressive intravenous resuscitation in patients receiv- 
ing rectal indomethacin and a control group receiving no prophylactic treatment.

\section{Material and methods}

This double blind controlled randomised clinical trial was conducted on 186 consecutive patients who underwent ERCP at Imam Khomeini Hospital, Ahvaz Jundishapur University of Medical Sciences, Ahvaz, Iran, between January 2014 and January 2015. The Medical Ethics Committee approved this study and it has been registered in the IRCT (Iranian Registry of Clinical of Trials) as number IRCT2015070323026N1. All patients signed an informed consent from before inclusion in the study.

The inclusion criteria were ERCP for standard clinical indications such as choledocholithiasis, bile duct leak, and biliary obstruction. Patients with cholangitis, sepsis, chronic pancreatitis, gallstone-related acute pancreatitis, balloon dilatation of papilla, history of post-ERCP pancreatitis, pregnancy, heart disease, risk factors for fluid overload, and those who needed pancreatic stent were excluded from study.

Patients were randomly assigned to three parallel groups, in a $1: 1: 1$ ratio. The first group $(n=62)$ received aggressive IVFR with a bolus of $20 \mathrm{ml} / \mathrm{kg}$ LRS immediately after ERCP, followed by $3 \mathrm{ml} / \mathrm{kg} / \mathrm{h}$ maintenance for $8 \mathrm{~h}$. The second group $(n=62)$ received $50 \mathrm{mg}$ rectal indomethacin immediately and $12 \mathrm{~h}$ after ERCP. The third group $(n=62)$ did not receive any prophylactic treatment. Blocked randomisation and double blind method was used in this trial. The patients and the clinical findings evaluator were blinded about the type of intervention.

The primary endpoint was acute post-ERCP pancreatitis based on hyperamylasaemia defined as serum amylase level $\geq 270 \mathrm{mg} / \mathrm{dl}$ at 8 and $24 \mathrm{~h}$ after the procedure and acute and severe epigastric pain. Patients were evaluated for pancreatic pain after surgery based on $0-10$ scale, defined as score $\geq 3$ and prolonged pain more than $24 \mathrm{~h}$ after intervention. Hospitalisation days, bilirubin, and creatinine serum levels, haematocrit, body mass index (BMI), history of pancreatic cancer, gallstone and sludge, and using balloon or basket or stent during procedure or in the past were also recorded for each patient. The pancreatitis degree was classified as mild, moderate, or severe based on hospitalisation of less than 4 days, 4 to 10 days, and longer than 10 days, respectively. None of the patients discontinued the study.

\section{Statistical analysis}

Statistical analysis was performed by SPSS package version 22 . All analyses were based on a two-sided test at the $p=0.05$ significance level. $\chi^{2}$, independent sample $t$ Student, one-way ANOVA, and repeated measure ANOVA tests were utilised to find any difference between categorical variables.

\section{Results}

Of 186 patients 102 (54.8\%) were female and $84(45.2 \%)$ were men with a mean age of 54 and 44 years, respectively. A total of 44 patients developed post-ERCP pancreatitis, of which 8 (12.9\%), 16 (25.8\%), and $20(32.3 \%)$ patients were in the IVFR, rectal indomethacin (RI), and control group, respectively. The incidence of post-ERCP pancreatitis in the three groups was not significantly different between male and female $(p=0.75)$. Table I shows the patients' clinical details. Baseline characteristics were well balanced between the three groups. Mean age, serum bilirubin,

Table I. Demographic characteristics of the patients

\begin{tabular}{|c|c|c|c|c|}
\hline Parameter & Fluid therapy & Indomethacin - rectal & Placebo & $P$-value \\
\hline Female, $n(\%)$ & $30(48.4)$ & $38(61.3)$ & $34(54.8)$ & 0.58 \\
\hline Male, $n(\%)$ & $32(51.6)$ & $24(38.7)$ & $28(54.2)$ & \\
\hline Age [year], mean & 54.24 & 57.97 & 56.25 & 0.19 \\
\hline Bilirubin [mg/dl] & $4.2 \pm 5.9$ & $3.7 \pm 3.8$ & $4 \pm 3.9$ & 0.12 \\
\hline Haematocrit (\%), mean \pm SD & $36 \pm 4$ & $37 \pm 5$ & $35 \pm 3$ & 0.03 \\
\hline Creatinine $[\mathrm{mg} / \mathrm{dl}]$, mean $\pm \mathrm{SD}$ & $0.7 \pm 0.2$ & $0.7 \pm 0.2$ & $0.7 \pm 0.2$ & 0.9 \\
\hline $\mathrm{BMI}\left(>30 \mathrm{~kg} / \mathrm{m}^{2}\right), n(\%)$ & $3(5)$ & $7(11.2)$ & 0 & 0.02 \\
\hline Women's age (<30 year), $n$ (\%) & $2(3.2)$ & 0 & $2(3.2)$ & 0.12 \\
\hline Women's age ( $\geq 30$ year), $n$ (\%) & $28(45.1)$ & $38(61.2)$ & $32(51.6)$ & 0.45 \\
\hline Pancreatic cancer, $n$ (\%) & $2(3.2)$ & $4(6.5)$ & $2(3.2)$ & 0.08 \\
\hline Gallstones, $n$ (\%) & $55(88.7)$ & $50(80.6)$ & $47(75.8)$ & 0.31 \\
\hline Sludge, $n(\%)$ & $5(8.1)$ & $8(12.9)$ & $13(20.9)$ & 0.51 \\
\hline
\end{tabular}


serum creatinine, history of pancreatic cancer, and history of gallstones and sludge were not significantly different between the three groups (Table I). Only $2.1 \%$ of females in the three groups were younger than 30 years of age. The rate of pancreatic pain significantly differed between the three groups IVFR, RI, and control (13 (21\%), 21 (33.9\%), and 27 (43.5\%) patients, respectively) $(p=0.046)$.

The serum amylase level increased in the three groups during $24 \mathrm{~h}$. The IVFR group had lower but not significant mean score with IR and control groups $(p=0.09)$. The mean score of serum amylase level was significantly lower in the IVFR group at $8 \mathrm{~h}$ compared with the IR and control groups $(p=0.02)$. Moreover, the mean score of serum amylase level remained lower but not significantly in the IVFR group compared with the IR and control groups $(p=0.2)$.

The procedures (ballooning to remove gallstones, basket, plastic stent, and needle knife between) did not affect the incidence of post-ERCP pancreatitis between the three groups ( $p=0.8,0.7,0.4$, and 0.2 , respectively) (Table II). One hundred and eighty-two out of
186 patients were older than 30 years of age, from which 8 (12.9\%), 16 (25.8\%), and 14 (22.4\%) patients developed post-ERCP pancreatitis in the IVFR, RI, and control group. The proportions of patients who were older than 30 years and also developed post-ERCP pancreatitis significantly differed between three groups $(p=0.015)$.

We also evaluated the impact of some risk factors on developing post-ERCP pancreatitis according to the American Society for Gastrointestinal Endoscopy (ASGE) guidelines, including normal bilirubin ( $\leq 1 \mathrm{mg}$ / $\mathrm{dl}$ ), pancreatic duct stones, sphincterotomy, and age (<30 years). Table III shows that only 1 out of 7 (11.3\%) patients who had normal bilirubin in the IVFR group developed post-ERCP pancreatitis. None of the 5 (8.06\%) patients with sphincterotomy developed post-ERCP pancreatitis. In total, IVFR and RI were equally more effective than in the control group in preventing postERCP pancreatitis.

Details of procedures performed during ERCP for the three groups are demonstrated in Table IV. In total, 8, 16 and 20 procedures were performed in the IVFR, IR, and control groups, respectively. Cholelithiasis was the most

Table II. Evaluated indices in three intervention groups

\begin{tabular}{|c|c|c|c|c|}
\hline Parameter & Hydration & Indomethacin & Placebo & $P$-value \\
\hline Pancreatic pain & 13 & 21 & 27 & 0.046 \\
\hline Amylase at $2 \mathrm{~h}[\mathrm{U} / \mathrm{ll}]$ & 95 & 115 & 199 & 0.09 \\
\hline Amylase at $8 \mathrm{~h}[\mathrm{U} / \mathrm{ll}]$ & 131 & 158 & 215 & 0.02 \\
\hline Amylase at $24 \mathrm{~h}[\mathrm{U} / \mathrm{l}]$ & 199 & 215 & 238 & 0.2 \\
\hline Hospitalisation [days] & 1.8 & 2.3 & 2.1 & 0.92 \\
\hline PEP (post-ERCP pancreatitis) & $8(12.9)$ & $16(25.8)$ & $20(32.3)$ & 0.036 \\
\hline Balloon to remove gallstone & $33(53.2)$ & $20(32.3)$ & $33(53.2)$ & 0.8 \\
\hline Basket & $3(5.3)$ & $1(0.016)$ & $3(5.3)$ & 0.7 \\
\hline Plastic stent & $9(5.14)$ & $2(0.032)$ & $9(5.14)$ & 0.4 \\
\hline Needle knife & $3(0.05)$ & $4(0.06)$ & $8(12.9)$ & 0.2 \\
\hline Pancreatitis in old age ( $\geq 30$ year) & $8(12.9)$ & $16(25.8)$ & $14(22.6)$ & 0.015 \\
\hline
\end{tabular}

Table III. Post ERCP pancreatitis risk factors according to ASGE guidelines

\begin{tabular}{lccc} 
Parameter & A & B & C \\
\hline Normal bilirubin $(\leq 1 \mathrm{mg} / \mathrm{dl})$ & $7(11.3)$ & $5(8.06)$ & 0 \\
PEP & 1 & $8(12.9)$ & $2(8.06)$ \\
2 & $14(22.5)$ \\
Pancreatic duct stones & $12(19.3)$ & 3 & $7(11.2)$ \\
PEP & 3 & $4(6.4)$ & 1 \\
\hline Sphincterotomy & $5(8.06)$ & 0 & $7(11.3)$ \\
PEP & 0 & $4(6.4)$ & 0
\end{tabular}

ASGE - American Society for Gastrointestinal Endoscopy Guidelines, PEP - post-ERCP pancreatitis, A-aggressive hydration, B - rectal-indomethacin, $C$ - placebo. 
common cause of ERCP in the three groups. No patient required metallic stent.

All patients in the IVFR group, who developed postERCP pancreatitis, reported pancreatic pain, whereas only 5 patients in this group without post-ERCP pancreatitis reported pancreatic pain. The overall rate of pancreatic pain in the three groups with and without pancreatic pain was similar (Table V). The abdominal pain score in post-ERCP pancreatitis was higher than in those who did not develop pancreatitis (Table V). Patients in the control group had higher pain score; however, all patients showed decreased pain score over time (Figure 1). Overall serum amylase levels in the three groups are depicted in Figure 2.

\section{Discussion}

In this study, aggressive IVFR with LRS significantly reduced the rate of post-ERCP pancreatitis and also decreased the abdominal pain score in comparison to the $\mathrm{RI}$ and control groups.

The IVFR may have serious adverse effects in certain conditions, such as in elderly patients or those who suffer from sodium-retaining disorders. Many clinicians are reluctant to administer aggressive IVFR and there is debate about the optimisation and risk-benefit assessment of this preventive modality. Buxbaum et al., in a pilot study of 62 patients at moderate risk, compared the risk of post-ERCP pancreatitis between ag- gressive IVFR ( $3 \mathrm{ml} / \mathrm{kg} / \mathrm{h}$ LRS during ERCP followed by a bolus of $20 \mathrm{mg} / \mathrm{kg}$ immediately after the procedure) with standard IVFR (continuous LRS infusion at rate of $1.5 \mathrm{ml} / \mathrm{kg}$ during ERCP and for $8 \mathrm{~h}$ thereafter). None of the patients in the aggressive IVFR group and $17 \%$ of the patients in the standard IVFR group developed post-ERCP pancreatitis [1]. In present study 44 patients developed pancreatitis, including 8 patients in the IVFR group (12.9\%), 16 patients in the RI group (25.8\%), and 20 patients in the control group (32.3\%). These rates significantly differed between the three groups ( $p=$ $0.036)$. The incidence rate of abdominal pain was lowest in the IVFR group. These rates significantly differed between the IVFR, IR, and control groups $(p=0.046)$. In a study by Dumonceau et al., administration of IVFR at a rate of $3 \mathrm{ml} / \mathrm{kg} / \mathrm{h}$ was associated with lower incidence of post-ERCP pancreatitis in comparison to an infusion rate of $1.5 \mathrm{ml} / \mathrm{kg} / \mathrm{h}$ [8]. Wu et al. showed that IVFR with LRS can reduce the incidence of systemic inflammation in patients with acute pancreatitis in comparison to fluid resuscitation with normal saline [9]. In a series of average risk patients by Shaygan-nejad et al., the rates of post-ERCP with aggressive and standard IVFR were $5.3 \%$ and $22.7 \%$, respectively ( $p=0.002$ ) [10].

Some investigations have mentioned that rectal indomethacin can decrease the risk of post-ERCP pancreatitis. The efficacy of pre-procedural rectal indomethacin versus post-procedure prescription drug in

Table IV. Details of procedures performed during ERCP

\begin{tabular}{lccccc} 
Group & $\begin{array}{c}\text { Only } \\
\text { sphincterotomy }\end{array}$ & $\begin{array}{c}\text { Sphincterotomy }+ \\
\text { balloon to remove } \\
\text { stone }\end{array}$ & $\begin{array}{c}\text { Basket }+ \\
\text { sphincterotomy }+ \\
\text { balloon to remove } \\
\text { stone }\end{array}$ & $\begin{array}{c}\text { Plastic stent }+ \\
\text { sphincterotomy }\end{array}$ & Metal stent \\
\hline A & $3(375)$ & $3(37.5)$ & $1(12.5)$ & $1(12.5)$ & 0 \\
\hline B & $9(56.2)$ & $7(43.8)$ & 0 & 0 & 0 \\
\hline C & $8(40)$ & $10(50)$ & 0 & $2(0.1)$ & 0
\end{tabular}

$A$-aggressive hydration, $B$-rectal-indomethacin, $C$ - placebo.

Table V. Status of pancreatic pain in patients with post-ERCP pancreatitis

\begin{tabular}{|c|c|c|c|c|}
\hline \multirow[t]{2}{*}{ Group } & \multirow[t]{2}{*}{ Pancreatic pain } & \multicolumn{2}{|c|}{ Post-ERCP pancreatitis } & \multirow[t]{2}{*}{ Total } \\
\hline & & Has not & Has & \\
\hline \multirow[t]{2}{*}{ A } & No & 49 (100) & 0 & 49 \\
\hline & Yes & $5(38.5)$ & $8(61.5)$ & 13 \\
\hline \multirow[t]{2}{*}{ B } & No & $41(100)$ & 0 & 41 \\
\hline & Yes & $5(23.8)$ & $16(76.1)$ & 21 \\
\hline \multirow[t]{2}{*}{ C } & No & $35(100)$ & 0 & 35 \\
\hline & Yes & $7(33.3)$ & $20(67.7)$ & 27 \\
\hline
\end{tabular}

A-hydration group, $B$-indomethacin-rectal group, $C$ - placebo. 


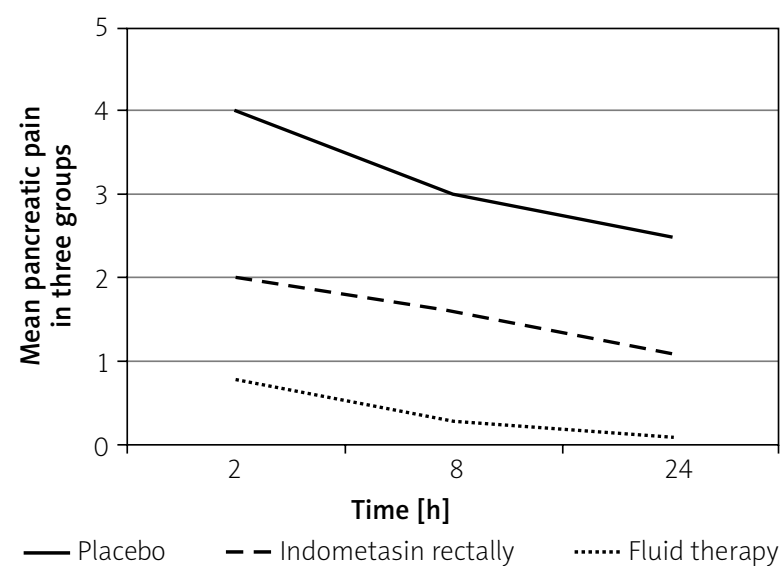

Figure 1. Trend of mean pancreatic pain changes during $24 \mathrm{~h}$ after ERCP in three groups

prevention of pancreatitis among patients undergoing ERCP procedure was recently investigated by Luo et al. [11]. In their study, 1297 patients were assigned to take pre-procedure rectal indomethacin in comparison with 1303 patients who received indomethacin after the procedure. Post-ERCP pancreatitis occurred in 47 (4\%) patients who received pre-procedure Indomethacin compared with 100 (8\%) patients in the post-procedure group. The frequency of post-ERCP pancreatitis in this study was $6 \%$. Absolute risk reduction was $4.1 \%$, equivalent to treatment of 25 patients to prevent one case of post-ERCP pancreatitis. The findings of this study suggest that pre-procedural administration of rectal indomethacin reduces the risk of post-ERCP pancreatitis by $53 \%$ compared with the post-procedure use of indomethacin. The frequency of post-ERCP pancreatitis among the patients of our study who received rectal indomethacin was higher (25.8\%) in comparison with the study by Luo et al. [11], and also Elmunzer's study (9\%) [1]. This difference can be due to selection of the patients and the experience of the specialist or interventional fellow during the procedure.

In a trial by Levenick et al., which was conducted on 449 patients undergoing ERCP procedure, the patients randomly divided into two groups, entailed a single dose of $100 \mathrm{mg}$ indomethacin or a placebo suppository during the procedure. Of those, $7.2 \%$ of patients in the indomethacin group versus $4.9 \%$ in the placebo group developed post-ERCP pancreatitis $(p=0.33)$. They concluded that rectal indomethacin did not prevent post-ERCP pancreatitis [12]. More recently, Levenick et al. published a study in which they concluded that RI does not prevent post-ERCP pancreatitis in consecutive patients [12]. They made this conclusion according to interim analysis. Furthermore, their sample size was reduced, so their trial did not have the power to extract such a conclusion.

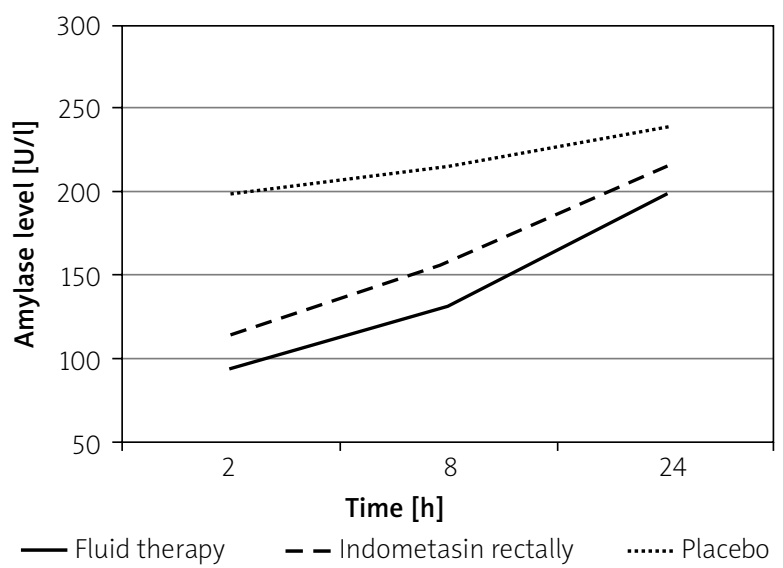

Figure 2. Mean amylase level changes in three groups of intervention over $24 \mathrm{~h}$ of follow-up

The current study had some advantages over previous studies, including larger sample size, and compared IVRF, RI, and control groups. We also evaluated parameters such as obesity, needle knife incision, and stone extraction by balloon, and the presence of pancreatic cancer, which have not been considered in previous studies [8, 9, 12-14].

Our study had some limitations. The study was performed in single referral hospital at Ahvaz, Iran. Adverse events of administration of rectal indomethacin such as the risk of gastro-intestinal bleeding were not investigated in this research. In addition, the efficacy of prophylactic placement of a pancreatic stent with concomitant use of indomethacin was not clarified in our study.

\section{Conclusions}

Aggressive fluid resuscitation with lactated Ringer's solution can effectively prevent post-ERCP pancreatitis in comparison to rectal indomethacin and no prophylactic measures.

\section{Acknowledgments}

This study was the final thesis (code $=9038$ ) of $\mathrm{Dr}$ Nima Aghamohammadi, fellowship of gastroenterology of Ahvaz Jundishapur University of Medical Sciences, Ahvaz, Iran. Special thanks to Ahvaz Imam Khomeini Hospital Clinical Research Development Unit (CREDI).

\section{Conflict of interest}

The authors declare no conflict of interest.

\section{References}

1. Elmunzer BJ. Aggressive intravenous fluid resuscitation for preventing post-endoscopic retrograde cholangiopancreatography pancreatitis: finally on the right track. Clin Gastroenterol Hepatol 2014; 12: 308-10. 
2. Andriulli, A, Loperfido S, Napolitano G, et al. Incidence rates of post-ERCP complications: a systematic survey of prospective studies. Am J Gastroenterol 2007; 102: 1781-8.

3. Cheng $C L$, Sherman $S$, Watkins JL, et al. Risk factors for post-ERCP pancreatitis: a prospective multicenter study. Am J Gastroenterol 2006; 101: 139-47.

4. Buxbaum J, Yan A, Yeh K, et al. Aggressive hydration with lactated Ringer's solution reduces pancreatitis after endoscopic retrograde cholangiopancreatography. Clin Gastroenterol Hepatol 2014; 12: 303-7 e1.

5. Badalov N, Tenner S, Baillie J. The prevention, recognition and treatment of post-ERCP pancreatitis. JOP 2009; 10: 88-97.

6. George S, Kulkarni A, Stevens G, et al. Role of osmolality of contrast media in the development of post-ERCP pancreatitis: a meta-analysis. Dig Dis Sci 2004; 49: 503-8.

7. Ding $X$, Chen $M$, Huang $S$, et al. Nonsteroidal anti-inflammatory drugs for prevention of post-ERCP pancreatitis: a meta-analysis. Gastrointest Endosc 2012; 76: 1152-9.

8. Dumonceau JM, Andriulli A, Elmunzer BJ, et al. Prophylaxis of post-ERCP pancreatitis: European Society of Gastrointestinal Endoscopy (ESGE) Guideline - updated June 2014. Endoscopy 2014; 46: 799-815.

9. Wu BU, Hwang JQ, Gardner TH, et al. Lactated Ringer's solution reduces systemic inflammation compared with saline in patients with acute pancreatitis. Clin Gastroenterol Hepatol 2011; 9: 710-7.e1.

10. Shaygan-nejad A, Masjedizadeh AR, Ghavidel A, et al. Aggressive hydration with lactated Ringer's solution as the prophylactic intervention for postendoscopic retrograde cholangiopancreatography pancreatitis: a randomized controlled double-blind clinical trial. J Res Med Sci 2015; 20: 838-43.

11. Luo H, Zhao L, Leung J, et al. Routine pre-procedural rectal indometacin versus selective post-procedural rectal indometacin to prevent pancreatitis in patients undergoing endoscopic retrograde cholangiopancreatography: a multicentre, single-blinded, randomised controlled trial. Lancet 2016; 387: 2293-301.

12. Levenick JM, Gordon SR, Fadden LL, et al. Rectal indomethacin does not prevent post-ERCP pancreatitis in consecutive patients. Gastroenterology 2016; 150: 911-7.

13. Hanna MS, Portal AJ, Dhanda AD, et al. UK wide survey on the prevention of post-ERCP pancreatitis. Frontline Gastroenterol 2014; 5: 103-10.

14. Yaghoobi M, Rolland S, Waschke KA, et al. Meta-analysis: rectal indomethacin for the prevention of post-ERCP pancreatitis. Aliment Pharmacol Ther 2013; 38: 995-1001.

Received: 13.07 .2016

Accepted: 27.09.2016 